Conclusion These reference data on right ventricular and atrial dimensions and volumes can be used for follow-up studies of boys and girls at 6-years-of-age. 3D volumes correlated moderately with BMI.

\section{EFFECT OF A PILOT INTERVENTION ON SETTING UP LONG-TERM MECHANISM OF NEONATAL RESUSCITATION TRAINING IN 4 COUNTIES IN CHINA}

doi:10.1136/archdischild-2012-302724.1140

${ }^{1} \mathrm{~T} \mathrm{Xu},{ }^{1} \mathrm{X}$ Jin, ${ }^{1} \mathrm{H}$ Wang, ${ }^{1} \mathrm{~L}$ Gong, ${ }^{2} \mathrm{X}$ Zheng, ${ }^{3} \mathrm{G} \mathrm{Yu},{ }^{4} \mathrm{G} \mathrm{Xu},{ }^{5} \mathrm{P}$ Zhang. ${ }^{\mathrm{T}}$ National Center for Women and Children's Health, China CDC, Beijing; ' ${ }^{2}$ Shandong Provincial Health Bureau, Jinan; ${ }^{3}$ Heilongjiang Provincial Health Bureau; ${ }^{4}$ Heilongjiang Maternal and Child Health Care Center, Haerbin; ${ }^{5}$ Shandong Maternal and Child Health Care Center, Jinan, China

Background and Aims Neonatal mortality is the leading cause of under-5 child deaths in China. The aim was to evaluate the effect of a pilot intervention on setting up long-term mechanism of neonatal resuscitation training in 4 counties in China.

Methods A neonatal resuscitation leading group was set up within each county level hospital to lead the in-hospital training, department coordination, resuscitation practices and cases audit. A random control survey was conducted in the intervention counties and 4 randomly selected control counties to evaluate the impact of the intervention. Indicators evaluated include knowledge and selfconfidence score of health providers, in-hospital regulations, changes of asphyxia incidence and mortality.

Results Over $90 \%$ of intervention hospitals had carried out neonatal resuscitation related regulations requiring that trained paediatricians participate in case discussion of high-risk delivery and onsite resuscitation, while in control hospitals less than $55 \%$ had such requirements. The average knowledge score of health providers was significantly higher in the intervention counties than the control counties (9.19 \pm 1.18 VS $8.40 \pm 1.52)$. The average self-confidence score in the two groups were $57.33 \pm 2.50$ and $54.09 \pm 8.19$ respectively. The incidence of birth asphyxia (defined as Apgar score $\leq 7$ ) decreased from $8.83 \%$ to $5.99 \%$ in the intervention counties, and the intrapartum-related deaths in the delivery room decreased from 27.60 to 5.03 per 100,000 . No significantly changes were found in the control counties.

Conclusions Setting up long-term mechanism of neonatal resuscitation training is an effective method to strengthen in-hospital training, build up capability for neonatal resuscitation and therefore, can decrease the incidence of neonatal asphyxia.

\section{THE DIAMETER OF CORONARY ARTERIES IN HEALTHY NEWBORNS AT BIRTH, ONE AND SIX MONTHS OF AGES}

doi:10.1136/archdischild-2012-302724.1141

'BS Karagol, '2UA Orun, 'A Zenciroglu, 'N Okumus, 'N Karadag, 'A Dursun, 'AA Kundak, ${ }^{2} S$ Karademir. 'Dr. Sami Ulus Maternity, Childrens' Education and Research Hospital, Division of Neonatology; 'Dr. Sami Ulus Maternity, Childrens' Education and Research Hospital, Division of Pediatric Cardiology, Ankara, Turkey

Objective The aim of this study was to determine accurate and validated $z$-score equations for the normal values of coronary diameters adjusted with growth changes of the neonates by testing three different time periods.

Methods Echocardiography was performed on 200 healthy neonates at birth, one and six months of ages. Several regression models for the left (LCA) and right coronary artery (RCA) diameters were tested with weight, height, body surface area and aortic annulus diameter. Reliable standards for the coronary artery diameters for healthy newborns by determining z-score equations with appropriate statistical validations were established.

Results The coronary diameters on birth measurements were strongly correlated with birth weight, height, surface area and the diameter of the aortic annulus (Pearson's $\mathrm{R}>0.8$, all $\mathrm{p}<0.01$ ). There were significant associations between the mean data of weight, height, body surface area, aortic annulus and the LCA and RCA diameters measurements of study subjects at birth, one and six months of ages $(p<0.05)$

Conclusion We present a new set of equations for neonatal z-score calculation on the basis of a large number of healthy neonates on three different time period consisting of birth, one and six month of ages. It is clear with this study that the growth in caliber of the coronary arteries is definite and progressive during postnatal time.

\section{SAFEGUARDING THE BRAINS OF OUR SMALLEST CHILDREN: SAFEBOOSC - THE PILOT STUDY}

doi:10.1136/archdischild-2012-302724.1142

${ }^{1} \mathrm{~S}$ Hyttel-Sørensen, ${ }^{2} \mathrm{~T}$ Austin, ${ }^{3} \mathrm{M}$ Benders, ${ }^{4} \mathrm{O}$ Claris, ${ }^{5} \mathrm{G}$ Dempsey, ${ }^{6} \mathrm{M}$ Fumagalli, ${ }^{7} \mathrm{C}$ Gluud, ${ }^{8} \mathrm{C}$ Hagmann, ${ }^{9} \mathrm{~L}$ Hellström-Westas, ${ }^{3 P}$ Lemmers, ${ }^{10} \mathrm{G}$ Naulaers, ${ }^{11} \mathrm{~A}$ Pellicer, ${ }^{12} \mathrm{G}$ Pichler, ${ }^{7} \mathrm{~L}$ Saem Støy, ${ }^{3} \mathrm{~F}$ van Bel, ${ }^{13} \mathrm{~W}$ van Oeveren, ${ }^{14} \mathrm{M}$ Wolf, ${ }^{15} \mathrm{G}$ Greisen. ${ }^{1}$ Copenhagen University Hospital Rigshospitalet, Copenhagen, Denmark; ${ }^{2}$ Rosie Maternity Hospital, Department of Paediatrics, Cambridge, UK; ' Wilhelmina Children's Hospital, Department of Neonatology, Utrecht, The Netherlands; ${ }^{4}$ Hospices Civils de Lyon, Department of Neonatology, Lyon, France; ${ }^{5}$ University College Cork, Department of Neonatology, Cork, Ireland; ' Università di Milano, Department of Maternal and Pediatric Sciences, Milan, Italy; ' Copenhagen Trial Unit, Rigshospitalet, Copenhagen, Denmark; ${ }^{8}$ University Hospital Zurich, Clinic of Neonatology, Zurich, Switzerland ${ }^{9}$ University Hospital Uppsala, Department of Neonatology, Uppsala, Sweden; ${ }^{10}$ Katholieke Universiteit Leuven, Department of Neonatology, Leuven, Belgium; ${ }^{11}$ La Paz University Hospital, Department of Neonatology, Madrid, Spain; ${ }^{12}$ Medical University of Graz, Department of Paediatrics, Graz, Austria; ${ }^{13}$ Haemoscan B.V., Groningen, The Netherlands; ${ }^{14}$ University Hospital Zurich, Biomedical Optics Research Laboratory, Zurich, Switzerland; ${ }^{15}$ Copenhagen University Hospital, Rigshospitalet, Copenhagen, Denmark

Background and Aims The SafeBoosC project aims to test the benefits and harms of cerebral near-infrared spectroscopy (NIRS) oximetry in infants born before 28 weeks of gestation. A phase II trial will randomise infants to cerebral NIRS oximetry and a treatment guideline during the first 72 hours of life or standard care with blinded NIRS-monitoring. The primary outcome is the area (burden) outside the normal ranges of $\mathrm{rStO}_{2}$ of 55 to $85 \%$.

Methods This pilot of the experimental group included 10 infants using the INVOS 5100C and NONIN EQUANOX 7600.

Results Median gestational age was 26 weeks +3 days. Median start-up time was 133 minutes after delivery. Median recording time was 69.7 hours. Mean $\mathrm{rStO}_{2}$ was $64.2+/-4.5 \%$. Median burden of hyper- and hypoxia was $30.3 \%$ hours (range 2.8-112.3). Clinical staff responded to out of range values 29 times - once was it to a value above $85 \%$. In comparison, there was 83 periods of more than 10 minutes with $\mathrm{rStO}_{2}$ below $55 \%$ and four episodes with $\mathrm{rStO}_{2}$ above $85 \%$. These periods accounted for $72 \%$ of the total burden of hypoxia. 18/29 of interventions were adjustments of $\mathrm{FiO}_{2}$ that 13 of 18 times resulted in an out of range $\mathrm{SpO}_{2}$. Two infants suffered burns.

Conclusions Early cerebral NIRS monitoring proved feasible, but prolonged periods of hypoxia went untreated, while adjustment of $\mathrm{FiO}_{2}$ often would result in $\mathrm{SpO}_{2}$ out of local target range. This points to a less than perfect implementation of the treatment guideline.

\section{PREDICTORS OF DUCT DEPENDENT CONGENITAL HEART DISEASE IN INFANTS TRANSFERRED BY NEWBORN EMERGENCY TRANSPORT SERVICE (NETS) VICTORIA}

doi:10.1136/archdischild-2012-302724.1143

${ }^{1,2} \mathrm{~N}$ Gupta, ${ }^{2,3} \mathrm{COF}$ Kamlin, ${ }^{2,4} \mathrm{M}$ Stewart, ${ }^{5} \mathrm{M}$ Cheung, ${ }^{4} \mathrm{~N}$ Patel. ${ }^{1}$ Neonatal Unit, John Radcliffe Hospital, Oxford, UK; ${ }^{2}$ Newborn Emergency Transport Services (NETS), Royal Children Hospital; ${ }^{3}$ Department of Newborn Research, Royal Womens Hospital, 